\title{
Data Warehouse using Assimilated Algorithm
}

\author{
D.Jeyapriya, S.Theivasigamani, R.Velvizhi,K.Shanmugapriya
}

\begin{abstract}
Information mined from the single source is analyzed and a report is made using first demand method of reasoning in the present structure. Be that as it may, this structure fails to help between related limit of data. [2 ],[ 4],[6]Consequently, an Interactive examination of data has been proposed, by empowering data to be shortened and seen in different ways. Data that can be shown as estimation attributes and estimated characteristics. Measure characteristics consolidate measure of some regard that can be totaled upon .e.g. the quality number of offers association. Center individual based data compromise count has been executed for hypothesis and disguise of data's in the data stockroom. Exceptional evasion strategy to manage mass data has been sent further in our proposed approach. Chain of significance on estimation characteristics of interrelated data has been proposed where it lets estimations to be seen at different levels of detail. The proposed reasoning is furthermore profitable toward the beginning of the observation strategy. $[1],[3],[5]$
\end{abstract}

\section{Index Terms: perception,OLAP,algorithm.}

\section{INTRODUCTION}

Realistic portrayal of logical information got by logical perceptions and preparing has been generally examined. The realistic portrayal of data has been restricted to authority ranges every one building up its own particular expert correspondence methods. Less consideration has been committed to representations of mind boggling and heterogeneous data interconnected with each other. Because of the expanded enthusiasm for human-PC cooperation to improve the ease of use and benevolence of figuring frameworks, representation procedures of logical data are as of late getting developing consideration. In addition, current basic leadership requires a more prominent ability to rapidly get differently interrelated information instead of single and disengaged data. Intellectual maps abridging connections without loss of points of interest are valuable backings. A wide arrangement of apparatuses is as of now accessible for visual portrayal of forbidden reports by methods for standard charts as Histograms, Pies et cetera. In any case, these

Revised Manuscript Received on June 22, 2019.

D.Jeyapriya,, Department of Computer Science and Engineering, Bharath Institute of Higher education and research, Chennai, India

S.Theivasigamani ,Deparrtment of CSE, Bharath Institute of Higher Education and Research Chenai,Thamilnadu ,India.

R.Velvizhi , Department of CSE ,Bharath Institute of Higher Education and Reaesrch,Chennai,Thamilnadu,India.

K.Shanmugapriya, Department of Computer Science and Engineering, Bharath Institute of Higher education and research, Chennai, India apparatuses generally just permit portrayal through isolated diagrams and can't picture connections between data contained in diverse reports. This paper introduces a rationale worldview to thoughtfully sort out the perception of reports and proposes a system to plan visual portrayals of connections between information given in unthinkable shape by misusing middle person based calculation. In the proposed framework we thoughtfully compose the Data distribution center reports. Intense equivocal strategy is utilized to deal with the mass information in the stockroom viably by defeating the progressed hesitant method. [7],[9] ,[11]

\section{MATERAILS AND METHODOLOGY}

A report is a twofold passage where title name indicates a solitary data thing, and every segment signifies a classification and an esteem. A chart is the perception of the data did by a report. In this manner, we call data thing a chart and its related report. The go between based calculation permits to sort out perceptions including more than one kind of charts that must be created and amassed. Through this model the client can outwardly speak to data things and their interrelationships at various levels of deliberation keeping consistency amongst things and ground information. The way toward sorting out data representation comprises essentially of four stages: 1. demonstrating of the psychological guide by depicting data things and their connections through coordination, 2. meaning of data to be removed as far as OLAP operations (i.e., OLAP Operation Pattern Definition), 3. Extraction of data in unthinkable shape (i.e., OLAP Operation), and 4.Perception of the last reports as a solitary picture (i.e., Report Visualization). [8],[ 10], [12]

The stage 1 permits altering the model speaking to the psychological guide of data to be imagined. The OLAP Operation Pattern Definition and OLAP Operation stages powerfully create reports relating to data things of the model. These reports are extricated from an information bazaar spoke to as a multidimensional block. The development of a report from an information store maps the 3D shape measurements on a structure created by one level pivot (comparing to the segments in the report) and at least one vertical tomahawks (relating to the information arrangement esteems). The subsequent report is separated by applying a mix of choice as well as total cutting/dicing/rotating/moving/boring dimensional administrators (i.e., the OLAP operations that permit multidimensional information investigation). We characterize operation design the mix of OLAP operations to be performed. Operation designs are communicated considering just metadata of the 
information store. The real execution of operation examples to remove information is performed amid the OLAP Operation stage toward the finish of the outline procedure. [13], [15] ,[ 17]

The main OLAP operation is turning, which pivots the $3 \mathrm{D}$ shape to put the measurement on the flat hub. A penetrating operation is performed on the flat pivot to build the points of interest. A dicing operation on the even hub is then performed to choose a subset of properties by barring the specific trait. At long last, a cutting operation on the vertical pivot diminishes the measurements to and delivers the report. The OLAP operation designs permit sorting out the perception at an appropriate conceptual level without considering the ground information. The model is characterized iteratively, in this way the approach permits an incremental development of the representations. Truth be told, the initial two stages of the plan procedure can be rehashed at whatever point the originator includes a data thing or a relationship to the model. This component improves the outline procedure of the perception. The OLAP Operation stage separates information from the multidimensional 3D square through the OLAP operation designs sorted out in the grid structure. OLAP handling could be moderate so the utilization of the cross section structure enhances the execution decreasing the aggregate number of OLAP operations to be performed. Truth be told, by abusing the fractional requesting connection between OLAP operation designs we figure the consequences of some OLAP operation designs beginning from the aftereffects of another. [14],[ 16], [18]

Accordingly, we locate the insignificant arrangement of OLAP operations producing the required OLAP operation designs. This set enables lessening the entrance to crude information to give the required reports

\section{RESULTS}

Current day PC applications have a need to get to, process, report and uncommonly incorporate information from different and dissimilar sources. [19],[21],[23].The information sources are made, kept up and distributed in positions that hold fast to their own particular association particular norms. Information reconciliation frameworks mean to give a solitary bound together interface to consolidating information in different configurations from those various sources. One of the primary methodologies in the combination of information is to utilize a Data Warehouse, where information from numerous information sources are extricated, changed and anticipated as another database, which is an accumulation of perspectives containing information. The information in the Data Warehouse might be organized uniquely in contrast to the source. Information is not new as the heap occurs at booked circumstances. Another type of information joining includes peers trading information in light of specific mappings. At the point when a question is postured to a companion, [20],[ 22], [24] it sends its information and additionally imports information from different associates. The information trade is an iterative procedure wherein each companion can thus import information from its neighboring associates in view of put stock seeing someone and there is no focal part dealing with the exchange of information. The information incorporation approach we talk about in this exploration work is the intervention framework or virtual information coordination framework that offers an inquiry interface over a solitary worldwide mapping. The worldwide diagram comprises of social predicates, as far as which the client can posture questions. In any case there is no genuine information contained in them. [25],[27],[29]

At the point when the go between gets an inquiry as far as the worldwide relations, it creates a question arrange for that distinguishes the applicable information sources and the significant information in them, and indicates how the information got from them must be joined to assemble the last answer. To deliver such an arrangement, the arbiter stores and procedures certain mappings or view definitions that partner the predicates in the worldwide diagram with those in the neighborhood sources. The Local-As-View (LAV) approach, which is utilized as a part of this examination work, characterizes the neighborhood source relations as perspectives over the worldwide construction .along these lines, each pertinent source connection can be characterized autonomously from other source relations. Thusly, it is less demanding for any source to join or leave the framework, without influencing other source definitions. The structure of the worldwide pattern and mappings constitute the metadata in a go between framework. [26],[28],[30]

The metadata will likewise contain imperatives and points of interest for getting to the information sources. The metadata depicts the idea of the information sources and information contained in them. The effective usage of a question arranging component depends on a legitimate outline, portrayal and questioning of metadata to separate required data. There are three primary calculations that plan to give question revamping under the LAV approach. The Bucket Algorithm actualized in the Information Manifold go between considers inquiries and view definitions that are conjunctive questions with examination predicates. [31],[33],[35]

On account of the Extended Minicon Algorithm, the inquiries and view definitions are conjunctive questions with correlation predicates. The great Inverse-RulesAlgorithm (IRA) acknowledges see definitions without correlation predicates yet handles utilitarian conditions, recursive inquiries and restricting example constraints. [32],[34],[36]

In stock relations, information from various sources is acquired in various archive designs and is put away in the information distribution center. These qualities are gotten by the client at various purpose of time. Likewise, the individual question postured by the client acquires values from the solid shape. The $3 \mathrm{D}$ shape is produced by bury relating the different document designs. The qualities for the question is acquired from the database are it is as of now present or amassed esteem is given. Various leveled display is utilized to bore down the database and get exact outcome. At least two records are entomb related and in view of the esteem show the outcome is given to the client. [37],[39],[41] 


\section{DISCUSSIONS}

Secluded The Data from different records are put away together in the information stockroom. The different reports incorporate XML, Excel, CSV documents. The qualities from the client are entered in the database which is put away in the coveted record arrange in the coveted area. These qualities are put away together keeping in mind the end goal to acquire exact outcomes. The inquiry postured by the client completes go between based calculation which the information from peers are gotten. In light of the outcome acquire a learning 3D shape is framed. The qualities from these solid shapes are finished by OLAP operations. [38],[40]The MDX extraction technique is utilized to acquire the qualities from the solid shapes. In this way the outcome acquired is additionally mapped in graphical organization. This procedure of giving graphical view helps in simple comprehension of the framework. The perception procedure enables various tables to be incorporated so as to give precise outcomes. The qualities got are past qualities entered in the database or amassed an incentive on the information in the database. Calculated association of data perception is introduced for a few applications on reports separated from a real information distribution center.

\section{CONCLUSION}

The representation of chart creation is broadly misused, however existing apparatuses just permit showing few sorts of straightforward connections. The proposed chart piece demonstrating procedure in view of the middle person based joining calculation gives rather a method to deal with the many-sided quality of Information to be spoken to. It merits accentuating that a fitting point of confinement must be put on the measure of information and reports that show up in any perception, all together not to surpass the limit of the spectator to outwardly deal with the multifaceted nature of the acquired picture. Cases of perspectives that present this kind of over-burden can be frequently found in Info designs applications where some of the time the visual portrayal underscores the enthusiastic and tasteful effect, even against an unmistakable comprehension of the information esteems. The representation configuration in view of this strategy drives the client to precisely choose data things to be shown as per their significance and interrelations. One of the points of this calculation is to help the opportunity of thought in the representation plan of complex information by giving an apparatus to deal with a formal deliberation of data things to be spoken to and associated. The most vital component of this formal deliberation is that it generally keeps the organized correspondence with ground information regardless of the structural unpredictability of the picture. The perceptions created by this procedure were effectively utilized as a part of a few reports. The diagram arrangement and the report representations is done to altogether enhance graphical recognition. This procedure of intellectual maps giving the data connections fundamental complex representation could likewise be valuable to contemplate a picture grouping methods and information mining applications.

\section{REFERENCES}

[1] Kumarave A., Rangarajan K.,Algorithm for automaton specification for exploring dynamic labyrinths, Indian Journal of Science and Technology,V-6,I-SUPPL5,PP-4554-4559,Y-2013

[2] P. Kavitha, S. Prabakaran "A Novel Hybrid Segmentation Method with Particle Swarm Optimization and Fuzzy C-Mean Based On Partitioning the Image for Detecting Lung Cancer" International Journal of Engineering and Advanced Technology (IJEAT) ISSN: 2249-8958, Volume-8 Issue-5, June 2019

[3] Kumaravel A., Meetei O.N.,An application of non-uniform cellular automata for efficient cryptography,2013 IEEE Conference on Information and Communication Technologies, ICT 2013,V-,I-,PP-1200-1205,Y-2013

[4] Kumarave A., Rangarajan K.,Routing alogrithm over semi-regular tessellations,2013 IEEE Conference on Information and Communication Technologies, ICT 2013,V-,I-,PP-1180-1184,Y-2013

[5] P. Kavitha, S. Prabakaran "Designing a Feature Vector for Statistical Texture Analysis of Brain Tumor" International Journal of Engineering and Advanced Technology (IJEAT) ISSN: 2249-8958, Volume-8 Issue-5, June 2019

[6] Dutta P., Kumaravel A.,A novel approach to trust based identification of leaders in social networks, Indian Journal of Science and Technology,V-9,I-10,PP--,Y-2016

[7] Kumaravel A., Dutta P.,Application of Pca for context selection for collaborative filtering,Middle - East Journal of Scientific Research,V-20,I-1,PP-88-93,Y-2014

[8] Kumaravel A., Rangarajan K.,Constructing an automaton for exploring dynamic labyrinths,2012 International Conference on Radar, Communication and Computing, ICRCC 2012,V-,I-,PP-161-165,Y-2012

[9] P. Kavitha, S. Prabakaran "Adaptive Bilateral Filter for Multi-Resolution in Brain Tumor Recognition" International Journal of Innovative Technology and Exploring Engineering (IJITEE) ISSN: 2278-3075, Volume-8 Issue-8 June, 2019

[10] Kumaravel A.,Comparison of two multi-classification approaches for detecting network attacks, World Applied Sciences Journal,V-27,I-11,PP-1461-1465,Y-2013

[11] Tariq J., Kumaravel A.,Construction of cellular automata over hexagonal and triangular tessellations for path planning of multi-robots,2016 IEEE International Conference on Computational Intelligence and Computing Research, ICCIC 2016,V-,I-,PP--,Y-2017

[12] Sudha M., Kumaravel A.,Analysis and measurement of wave guides using poisson method,Indonesian Journal of Electrical Engineering and Computer Science,V-8,I-2,PP-546-548,Y-2017

[13] Ayyappan G., Nalini C., Kumaravel A.,Various approaches of knowledge transfer in academic social network,International Journal of Engineering and Technology,V-,I-,PP-2791-2794,Y-2017

[14] Kaliyamurthie, K.P., Sivaraman, K., Ramesh, S. Imposing patient data privacy in wireless medical sensor networks through homomorphic cryptosystems 2016, Journal of Chemical and Pharmaceutical Sciences 92.

[15] Kaliyamurthie, K.P., Balasubramanian, P.C. An approach to multi secure to historical malformed documents using integer ripple transfiguration 2016 Journal of Chemical and Pharmaceutical Sciences 92 .

[16] A.Sangeetha,C.Nalini,"Semantic Ranking based on keywords extractions in the web", International Journal of Engineering \& Technology, 7 (2.6) (2018) 290-292

[17] S.V.GayathiriDevi,C.Nalini,N.Kumar,"An efficient software verification using multi-layered software verification tool "International Journal of Engineering \& Technology, 7(2.21)2018 454-457

[18] C.Nalini,ShwtambariKharabe,"A Comparative Study On Different Techniques Used For Finger - Vein Authentication", International Journal Of Pure And Applied Mathematics, Volume 116 No. 8 2017, 327-333, Issn: 1314-3395

[19] M.S. Vivekanandan and Dr. C. Rajabhushanam, "Enabling Privacy Protection and Content Assurance in Geo-Social Networks", International Journal of Innovative Research in Management, Engineering and Technology, Vol 3, Issue 4, pp. 49-55, April 2018.

[20] Dr. C. Rajabhushanam, V. Karthik, and G. Vivek, "Elasticity in Cloud Computing", International Journal of Innovative Research in Management, Engineering and Technology, Vol 3, Issue 4, pp. 104-111, April 2018.

[21] K. Rangaswamy and Dr. C. Rajabhushanamc, 
"CCN-Based Congestion Control Mechanism In Dynamic Networks", International Journal of Innovative Research in Management, Engineering and Technology, Vol 3, Issue 4, pp. 117-119, April 2018.

[22] Kavitha, R., Nedunchelian, R., "Domain-specific Search engine optimization using healthcare ontology and a neural network backpropagation approach", 2017, Research Journal of Biotechnology, Special Issue 2:157-166

[23] Kavitha, G., Kavitha, R., "An analysis to improve throughput of high-power hubs in mobile ad hoc network" , 2016, Journal of Chemical and Pharmaceutical Sciences, Vol-9, Issue-2: 361-363

[24] Kavitha, G., Kavitha, R., "Dipping interference to supplement throughput in MANET" , 2016, Journal of Chemical and Pharmaceutical Sciences, Vol-9, Issue-2: 357-360

[25] Michael, G., Chandrasekar, A.,'Leader election based malicious detection and response system in MANET using mechanism design approach", Journal of Chemical and Pharmaceutical Sciences(JCPS) Volume 9 Issue 2, April - June 2016.

[26] Michael, G., Chandrasekar, A.,"Modeling of detection of camouflaging worm using epidemic dynamic model and power spectral density", Journal of Chemical and Pharmaceutical Sciences(JCPS) Volume 9 Issue 2, April - June 2016.

[27] Pothumani, S., Sriram, M., Sridhar, J., Arul Selvan, G., Secure mobile agents communication on intranet,Journal of Chemical and Pharmaceutical Sciences, volume 9, Issue 3, Pg No S32-S35, 2016

[28] Pothumani, S., Sriram, M., Sridhar, Various schemes for database encryption-a survey, Journal of Chemical and Pharmaceutical Sciences, volume 9, Issue 3, Pg NoS103-S106, 2016

[29] Pothumani, S., Sriram, M., Sridhar, A novel economic framework for cloud and grid computing, Journal of Chemical and Pharmaceutical Sciences, volume 9, Issue 3, Pg No S29-S31, 2016

[30] Priya, N., Sridhar, J., Sriram, M. "Ecommerce Transaction Security Challenges and Prevention Methods- New Approach" 2016 ,Journal of Chemical and Pharmaceutical Sciences, JCPS Volume 9 Issue 3.page no:S66-S68 .

[31] Priya, N.,Sridhar,J.,Sriram, M."Vehicular cloud computing security issues and solutions" Journal of Chemical and Pharmaceutical Sciences(JCPS) Volume 9 Issue 2, April - June 2016

[32] Priya, N., Sridhar, J., Sriram, M. "Mobile large data storage security in cloud computing environment-a new approach" JCPS Volume 9 Issue 2. April - June 2016

[33] Anuradha.C, Khanna.V, "Improving network performance and security in WSN using decentralized hypothesis testing "Journal of Chemical and Pharmaceutical Sciences(JCPS) Volume 9 Issue 2. April - June 2016 .

[34] Anuradha.C, Khanna.V, "A novel gsm based control for e-devices" Journal of Chemical and Pharmaceutical Sciences(JCPS) Volume 9 Issue 2, April - June 2016.

[35] Anuradha.C, Khanna.V, "Secured privacy preserving sharing and data integration in mobile web environments " Journal of Chemical and Pharmaceutical Sciences(JCPS) Volume 9 Issue 2, April - June 2016 .

[36] Sundarraj, B., Kaliyamurthie, K.P. Social network analysis for decisive the ultimate classification from the ensemble to boos accuracy rates 2016 International Journal of Pharmacy and Technology 8

[37] Sundarraj, B., Kaliyamurthie, K.P. A content-based spam filtering approach victimisation artificial neural networks 2016 International Journal of Pharmacy and Technology 83.

[38] Sundarraj, B., Kaliyamurthie, K.P. Remote sensing imaging for satellite image segmentation 2016 International Journal of Pharmacy and Technology 83 .

[39] Sivaraman, K., Senthil, M. Intuitive driver proxy control using artificial intelligence2016 International Journal of Pharmacy and Technology $8 \quad 4$

[40] Sivaraman, K., Kaliyamurthie, K.P. Cloud computing in mobile technology2016 Journal of Chemical and Pharmaceutical Sciences 92.

[41] Sivaraman, K., Khanna, V.Implementation of an extension for browser to detect vulnerable elements on web pages and avoid click jacking 2016 Journal of Chemical and Pharmaceutical Sciences 92.

\section{AUTHORS PROFILE}
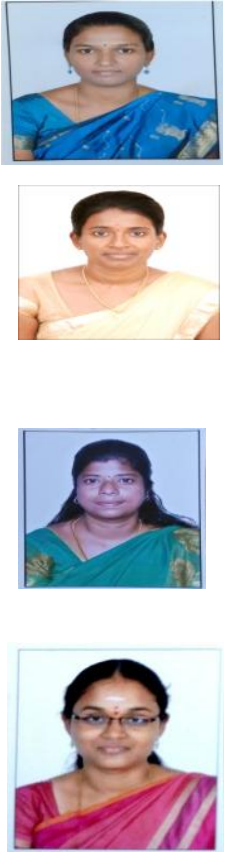

Mrs.D.Jeyapriya, Assistant Professor, Department of Computer Science \& Engineering, Bharath Institute of Higher Education and Research, Chennai, India

S.Theivasigamani ,Deparrtment of CSE, Bharath Institute of Higher Education and Research Chenai,Thamilnadu ,India

R.Velvizhi ,Deparrtment of CSE, Bharath Institute of Higher Education and Research Chenai,Thamilnadu ,India

Mrs.K.Shanmugapriya, Assistant Professor, Department of Computer Science \& Engineering, Bharath Institute of Higher Education and Research, Chennai, India 